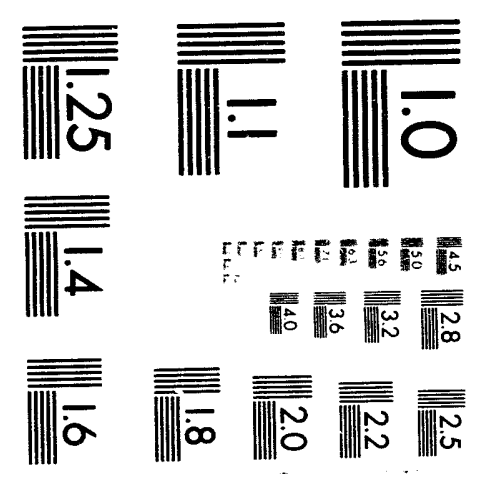



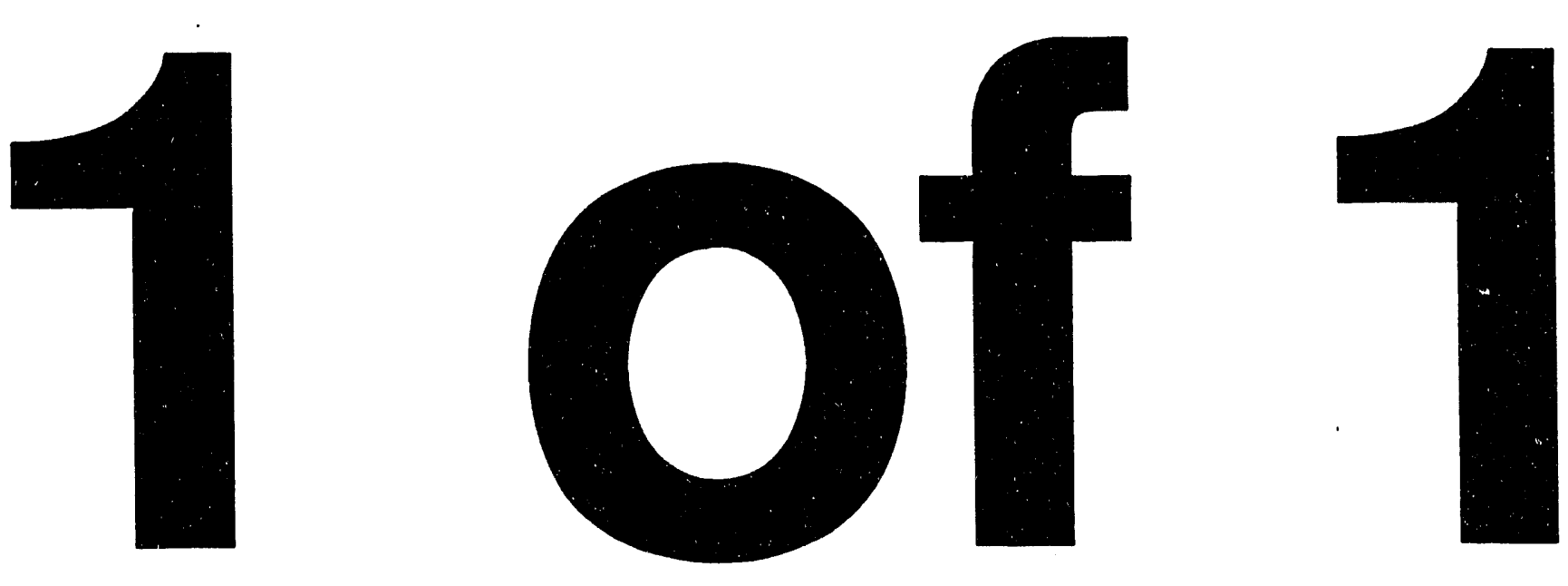


\title{
Radiative Flux Calculations at UV and Visible Wavelengths
}

\author{
A.S. Grossman \\ K.E. Grant \\ D. J. Wuebbles
}

October 1993

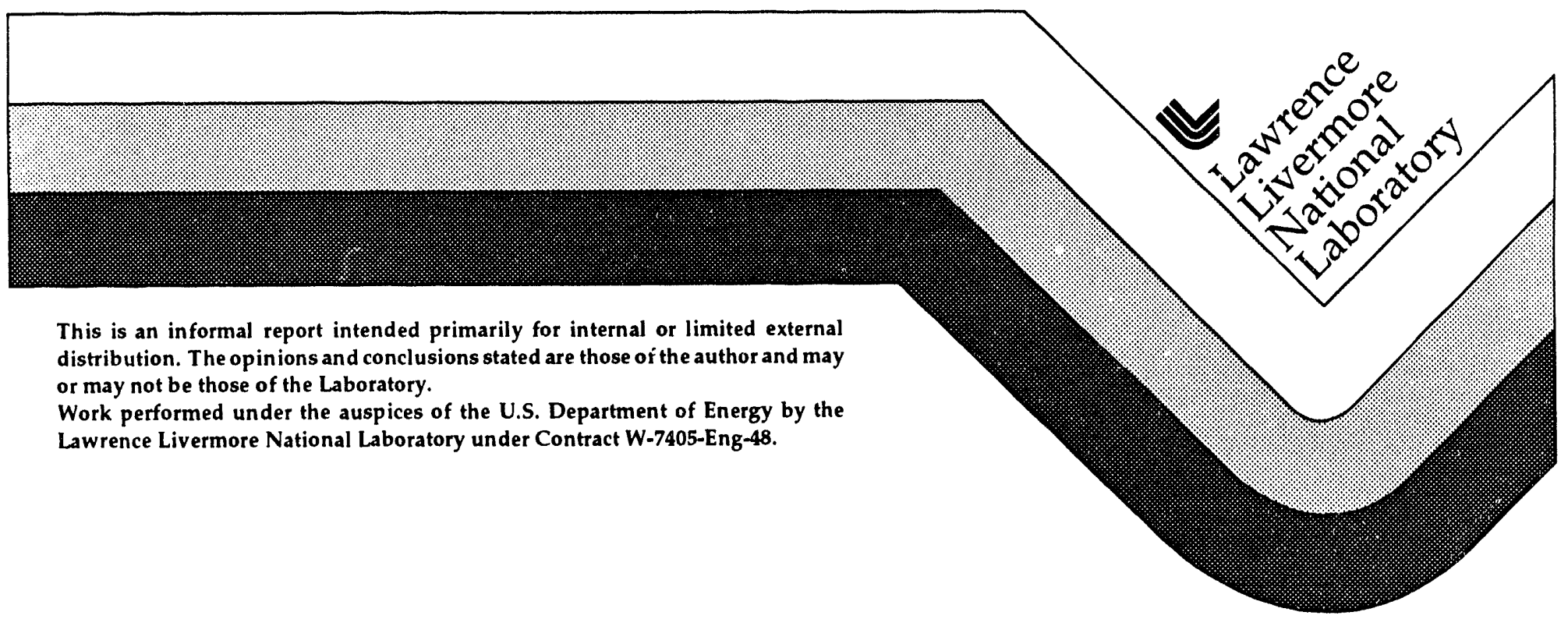




\section{DISCLAIMER}

This document was prepared as an acccount of work sponsored by an agency of the United States Government. Neither the United States Government nor the University of California nor any of their employees, makes any warranty, express or implied, or assumes any legal liability or responsibility for the accuracy, completeness, or usefulness of any information, apparatus, product, or process disclosed, or represents that its use would not infringe privately own rights. Reference herein to any specific commercial products, process, or service by trade name, trademark, manufacturer, or otherwise, does not necessarily constitute or imply its endorsement, recommendation, or favoring by the United States Government or the University of California. The views and opinions of authors expressed herein do not necessarily state or reflect those of the United States Government or the University of California, and shall not be used for advertising or product endorsement purposes.

This report has been reproduced directly from the best available copy.

Available to DOE and DOE contractors from the Office of Scientific and Technical Information P.O. Box 62, Oak Ridge, TN 37831

Prices available from (615) 576-8401, FTS 626-8401

Available to the public from the National Technical Information Service

U.S. Department of Commerce 5285 Port Royal Rd., Springfielr, VA 22161 


\title{
RADIATIVE FLUX CALCULATIONS AT UV AND VISIBLE WA VELENGTHS
}

\author{
Allen S. Grossman \\ Keith E. Grant \\ Donald J. Wuebbles \\ Global Climate Research Division \\ Lawrence Livermore National Laboratory \\ Livermore California 94550
}

September 1993

\section{INTRODUCTION}

A radiative transfer model to calculate the short wavelength fluxes at altitudes between 0 and $80 \mathrm{~km}$ has been developed at LLNL (Grant and Grossman, 1993). The wavelength range extends from $175-735 \mathrm{~nm}$. This spectral range covers the UV-B wavelength region, 250 - $350 \mathrm{~nm}$, with sufficient resolution to allow comparison of UV-B measurements with theoretical predictions. Validation studies for the model have been made for both UV-B ground radiation calculations and tropospheric solar radiative forcing calculations for various ozone distributions. These studies indicate that the model produces results which agree well with respect to existing UV calculations from other published models.

\section{RADIATIVE TRANSFER MODEL}

The input parameters to the radiative transfer model are;

1. Atmosphere Profile,

a. pressure levels $(\mathrm{mb})$,

b. average pressures $(\mathrm{mb})$,

c. average temperatures $(\operatorname{deg} \mathrm{K})$,

d. average densities $\left(\mathrm{g} / \mathrm{cm}^{3}\right)$,

e. average $\mathrm{O}_{3}$ mixing ratios (vol),

2. Altitude resolution,
a. $1 \mathrm{~km}-0-20 \mathrm{~km}$ altitude,
b. $2 \mathrm{~km}-20-80 \mathrm{~km}$ altitude,

3. Solar Zenith Angle,

4. Surface Albedo at each wavelength.

5. Single scattering albedo and asymmetry factors at each wavelength. 
The zero-atmosphere solar flux in each wavelength bin is taken from Connell and Wuebbles (1983) and is similar to WMO-16 (1985). Using data from Allen (1985) for the zero-atmosphere solar flux beyond $735 \mathrm{~nm}$, the calculated solar constant is $1368 \mathrm{~W} / \mathrm{m}^{2}$. The IPCC 1994 standard is $1370 \mathrm{~W} / \mathrm{m}^{2}$. Ozone cross sections have been taken from DeMore et al. (1992) and include temperature and pressure dependence. Other atmospheric trace gases such as $\mathrm{NO}_{2}$ and $\mathrm{SO}_{2}$ can effect UV levels, particularly in polluted urban environments, but for the initial validation studies we consider ozone absorption and Rayleigh scattering as the major sources of lower atmospheric extinction in the short wavelength spectral range. Rayleigh scattering cross sections have been taken from Nicolet (1984). A two-stream flux model is used to calculate the diffuse irradiance incident on each atmospheric layer. The sources of upwards and downwards diffuse irradiance, due to scattering from the direct beam, are obtained by the use of a deltaEddington approximation (King and Harshvardhan, 1986). The single layer treatment for incident diffuse irradiance is treated by the Sagan-Pollack model for the diffuse reflection and transmission factors (Sagan and Pollack, 1976). The radiative transfer equations for a atmosphere model have been solved for the fluxes at each level using an adding method similar to that published by Grant and Hunt(1969) and Harshvardhan et. al (1987). At solar zenith angles greater than 75 degrees, the direct optical beam path is calculated using spherical geometry. For solar zenith angles between than 70 degrees and 75 degrees a weighted average of the plane parallel and spherical geometries is used. Clouds have not been included in the initial validation studies although the radiative transfer model has the capacity for clouds to be included in the flux calculations.

\section{VALIDATION STUDIES}

The short wave model has been used to calculate UV- A and B ground fluxes in the wavelength range $250-400 \mathrm{~nm}$ for comparison with the results of Madronich (1993, "MAD"). The atmospheric profile used was the US Standard Atmosphere (1976) and the surface albedo was 0.05 . Figures 1-3 show the comparison of ground and solar fluxes between the LLNL and the MAD calculations at solar zenith angles of 60 and 80 degrees. Figure 1 shows the comparisons of solar and ground fluxes at a 60 degree zenith angle. Curves SFLXASG and GFLXASG are the LLNL calculations and curves SFLUXMAD and GFLUXMAD are the MAD calculations. Figure 2 shows a magnified segment of Figure 1. Figure 3 shows the ground flux comparison for solar zenith angle of 80 degrees. Curve GIFLXASG is the LLNL calculation and cur GIFLXMAD is the MAD calculation. Agreement between the LLNL and MAD calculations is within about ten percent. These differences can be directly correlated to differences in solar input flux. MAD also gives the result of a calculation in which the tropospheric ozone column was increased by 35 DU ( 78 percent) and the stratospheric ozone column was decreased by $35 \mathrm{DU}(\sim 12$ percent) while keeping the total ozone column constant at $345 \mathrm{DU}$. He finds that the surface dose change is of the order of 1 percent less than the normal abundance case at a 60 degree solar zenith angle. Using the LLNL model to evaluate the relative flux change at the $310 \mathrm{~nm}$ erythema dose maximum for a $30 \mathrm{DU} \mathrm{O}_{3}$ tropospheric increase and a $30 \mathrm{DU} \mathrm{O}_{3}$ stratospheric decrease, we find a relative flux change of $\sim 1.5$ percent less than the normal abundance case. At a solar zenith angle of 80 degrees we find a relative flux change of $\sim 10$ percent more than the normal abundance case while the MAD results predict a change of $\sim 9$ percent more than the normal abundance case. This is in reasonable agreement with the MAD results. Also the relative flux change should reverse sign at high solar zenith angles because the average path for scattered radiation becomes less than the direct transmission path length at the high zenith angles. This is also demonstrated by the LLNL model. 
The IPCC 1994 committee has provided a test case for the evaluation of $\mathrm{O}_{3}$ tropospheric radiative forcing to which the LLNL short wave model can be applied. The test case uses a McClatchey mid latitude, summer, clear sky approximation for the temperature, pressure and $\mathrm{O}_{3}$ abundance as a function of altitude. The tropopause was set at $179 \mathrm{mb}$. The surface albedo was set to 0.1 , the solar zenith angle was set to 59 degrees and the fraction of the day with the sun up was 0.557 . The test case was represented by a tropospheric increase in $\mathrm{O}_{3}$ abundance and a stratospheric decrease in $\mathrm{O}_{3}$ abundance. The following procedure was used to obtain the $\mathrm{O}_{3}$ changes (Shine, 1993). At altitudes below $8 \mathrm{~km}$, there is a uniform increase of 8 percent in the $\mathrm{O}_{3}$ abundance. At altitudes between 8 $\mathrm{km}$ and the tropopause, the fractional change in $\mathrm{O}_{3}$ abundance decreases linearly with altitude to zero. At altitudes above the tropopause $(-13 \mathrm{~km})$, the shape of the $\mathrm{O}_{3}$ change is the same as the S2 profile described by Schwarzkopf and Ramaswamy (1993) and normalized to a total loss of stratospheric ozone of $\sim 15.55$ DU. Table 1 gives a comparison of the $\mathrm{O}_{3}$ tropospheric radiative forcing results calculated using the LLNL model with the preliminary IPCC 1994 results from all the models used in the IPCC test calculations (Shine, 1993).

TABLE 1 .

\begin{tabular}{|c|c|c|c|}
\hline \multicolumn{4}{|c|}{$\mathrm{O}_{3}$ RADIATIVE FORCING COMPARISON $175-735 \mathrm{~nm}\left(\mathrm{~W} / \mathrm{m}^{2}\right)$} \\
\hline & Tropo + Strat & Tropo. only & Strat. only \\
\hline LLNL & 0.2779 & 0.0227 & 0.2549 \\
\hline IPCC & $0.241-0.392$ & $0.015-0.031$ & $0.226-0.361$ \\
\hline
\end{tabular}

Table 1 shows that the LLNL results are situated right in the middle of the range of $\mathrm{O}_{3}$ tropospheric radiative forcing results.

We have provided tests of the validity of the LLNL short wavelength radiative transfer model in the UV-B and UV-A wavelength ranges and found that it produces ground flux results which agree very well with published calculations. We have also provided test cases which show that the $\mathrm{O}_{3}$ tropospheric radiative forcing over the entire wavelength range of $175-735 \mathrm{~nm}$ agrees quite well with similar calculations performed under the IPCC 1994 test scenarios.

\section{ACKNOWLEDGEMENT}

Work was performed under the auspices of the U.S. Department of Energy by the Lawrence Livermore National Laboratory under contract No. W-7405-Eng-48 and was supported in part by the Department of Energy Office of Environmental Analysis.

\section{REFERENCES}

Allen, C.W., 1985: Astrophysical Quantities, 3rd. Edition, 310 pp., Athlone Press, London, England.

Connell, P., and D.W. Wuebbles, 1983: Summary of photochemical and radiative data used in the LLNL one-dimensional transport-kinetics model of the troposphere and stratosphere: 1982. LLNL Report UCID-19657-82, Jan. 1983.

DeMore, W.B., S.P. Sander, D.M. Golden, R.F. Hampson, M.J. Kurylo, C.J. Howard, A.R. Ravishankara, C.E. Kolb, and M.J. Molina, 1992: Chemical kinetics and photochemical data for use in stratospheric modeling: Evaluation 10, NASA JPL Report JPL Publication 92-20, August 1992. 
Grant K.E., and A.S. Grossman, LLNL Report UCRL (in press).

Grant I.P., and G.E. Hunt, 1969: Discrete space theory of radiative transfer. 1. Fundamentals, Proc. R. Soc. London, Ser. A, 313, pp. 183-197.

Harshvardhan, R. Davies, D.A. Randall, and T.G. Corsetti, 1987: A fast radiation parameterization for atmospheric circulation models, J. Geophys. Res. , Vol. 92 , D1, pp. 1009-1016.

King, M.D., and Harshvardhan, 1986, Comparative accuracy of selected multiple scattering approximations, J. Atmos. Sci. , 43, pp. 784-801.

Madronich, S., 1993, Chapter 2: UV radiation in the natural and perturbed atmosphere, Effects of UV-B Radiation On Humans, Animals, Plants, Microorganisms and Materials, edited by M. Trevini, Lewis Publishers/CRC Press, (in press).

Nicolet, M., 1984: On the molecular scattering in the terrestrial atmosphere: An empirical for its calculation in the homosphere, Planet, and Space Sci., 32, 1467-1468.

Sagan, C., and J.B. Pollack, 1967: An isotropic nonconservative scattering and the clouds of Venus, J. Geophys. Res., 72, pp. 469-477.

Schwarzkopf, M.D., and V. Ramaswamy, 1993: Radiative forcing due to ozone in the 1980s: Dependence on altitude of ozcne change, Geophys. Res. Letts., Vol 20, No 2 , pp. 205-208.

Shine, K., 1993, private communication.

US Standard Atmosphere, 227 pp., 1976, National Oceanic and Atmospheric Administration (NOAA), National Aeronautics and Space Administration (NASA), United States Air Force, NOAA-S/T 76-1562, Washington D.C.

WMO-16, 1985: Atmospheric ozone 1985: Assessment of our understanding of the processes controlling its present distribution and change, Vol. 1, Report No. 16, World Meteorological Organization, pp. 349-378.

\section{FIGURE CAPTIONS}

Figure 1.The comparisons of solar and ground fluxes $\left(\mathrm{W} / \mathrm{m}^{2}\right)$ as a function of wavelength (nm) at a 60 degree zenith angle. Curves SFLXASG and GFLXASG are the LLNL calculations and curves SFLUXMAD and GFLUX $M A D$ are the MAD calculations.

Figure 2. The comparisons of ground fluxes $\left(\mathrm{W} / \mathrm{m}^{2}\right)$ as a function of wavelength $(\mathrm{nm})$ at a 60 degree zenith angle. Curves SFLXASG and GFLXASG are the LLNL calculations and curves SFLUXMAD and GFLUX MAD are the MAD calculations.

Figure 3. The comparison of ground flux $\left(\mathrm{W} / \mathrm{m}^{2}\right)$ as a function of wavelength $(\mathrm{nm})$ comparison for a solar zenith angle of 80 degrees. Curve G1FLXASG is the LLNL calculation and curve GIFLXMAD is the MAD calculation. 
COMPARISON SOLAR-GROUND UV-B FLUX $\left(60^{\circ}\right.$ SOLAR ZENITH ANGLE)

$E$
E
$\frac{N}{3}$
$\frac{x}{3}$
$\frac{1}{u}$

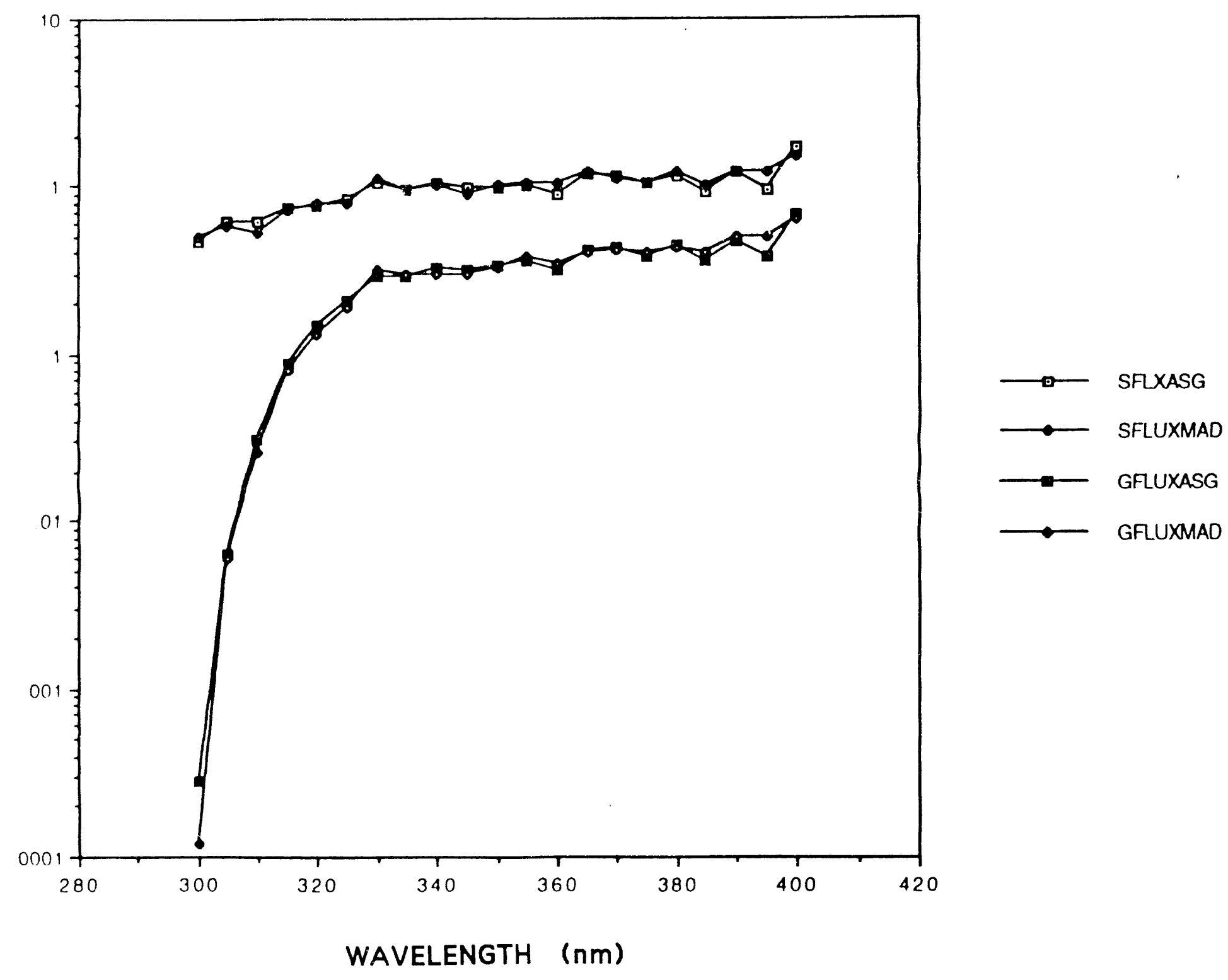


COMPARISON SOLAR-GROUND UV-B FLUX (60 SOLAR ZENITH ANGLE)

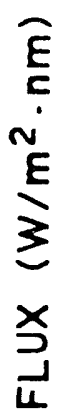

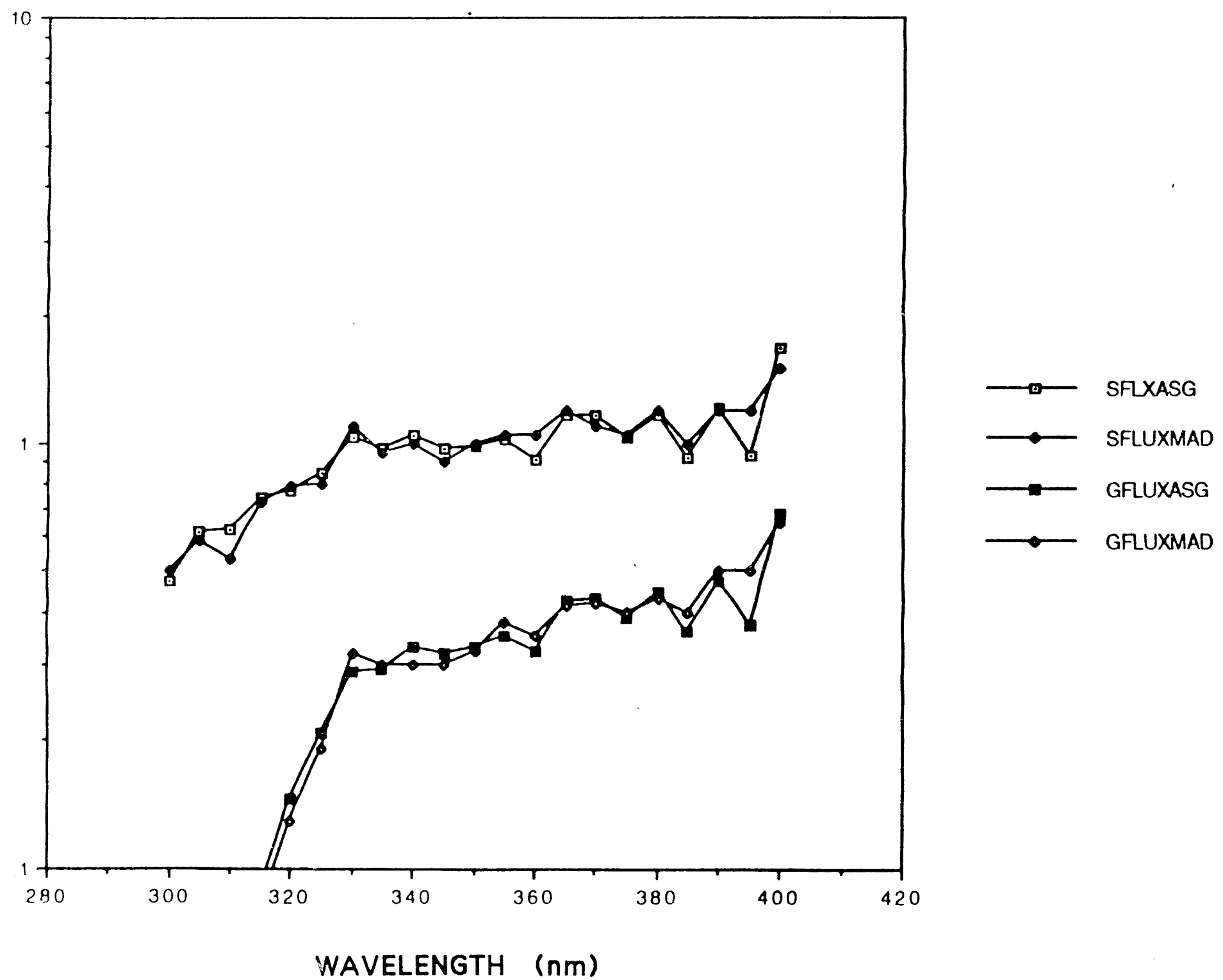


COMPARISON SOLAR-GROUND UV-B FLUX (80 SOLAR ZENITH ANGLE)

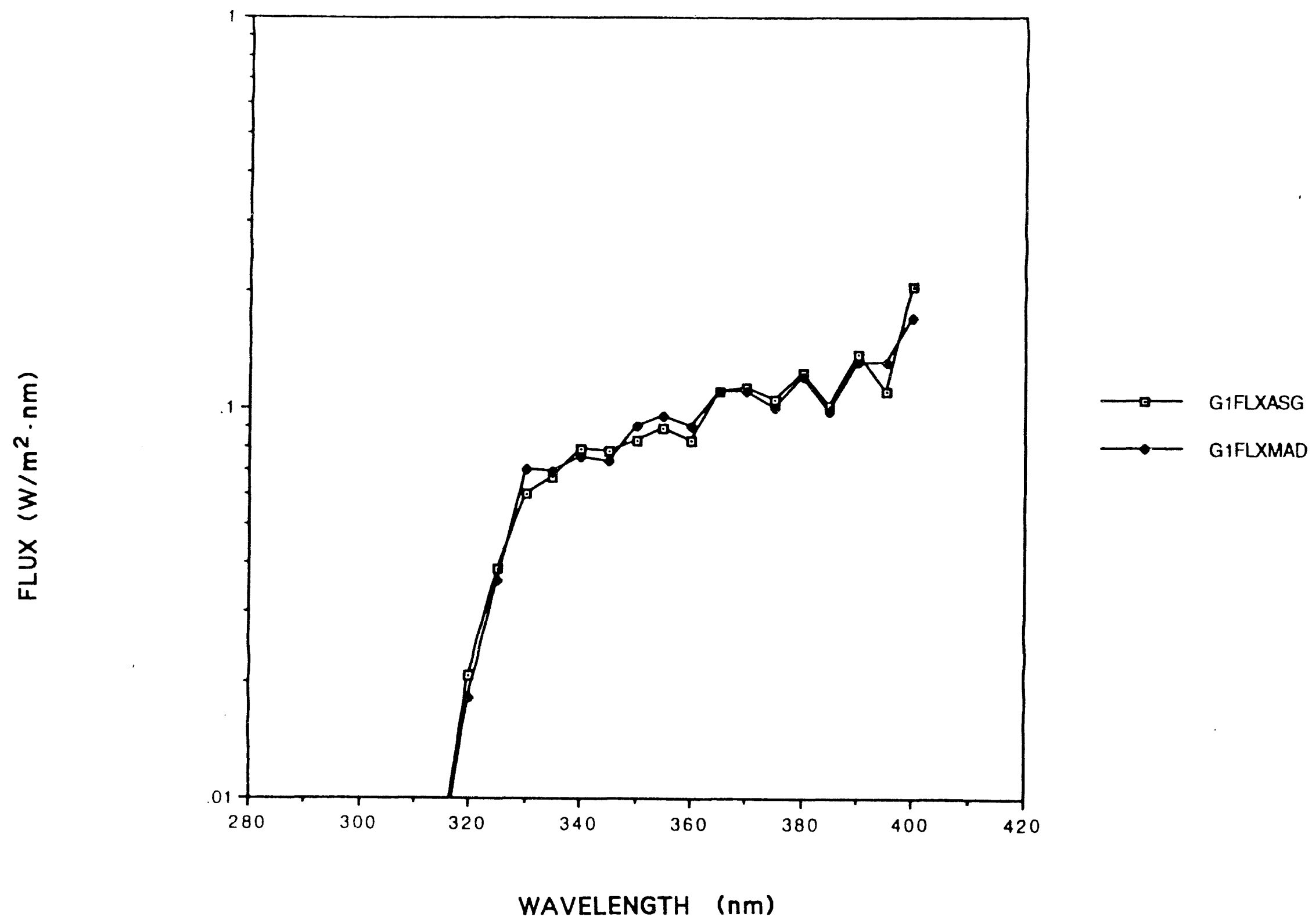



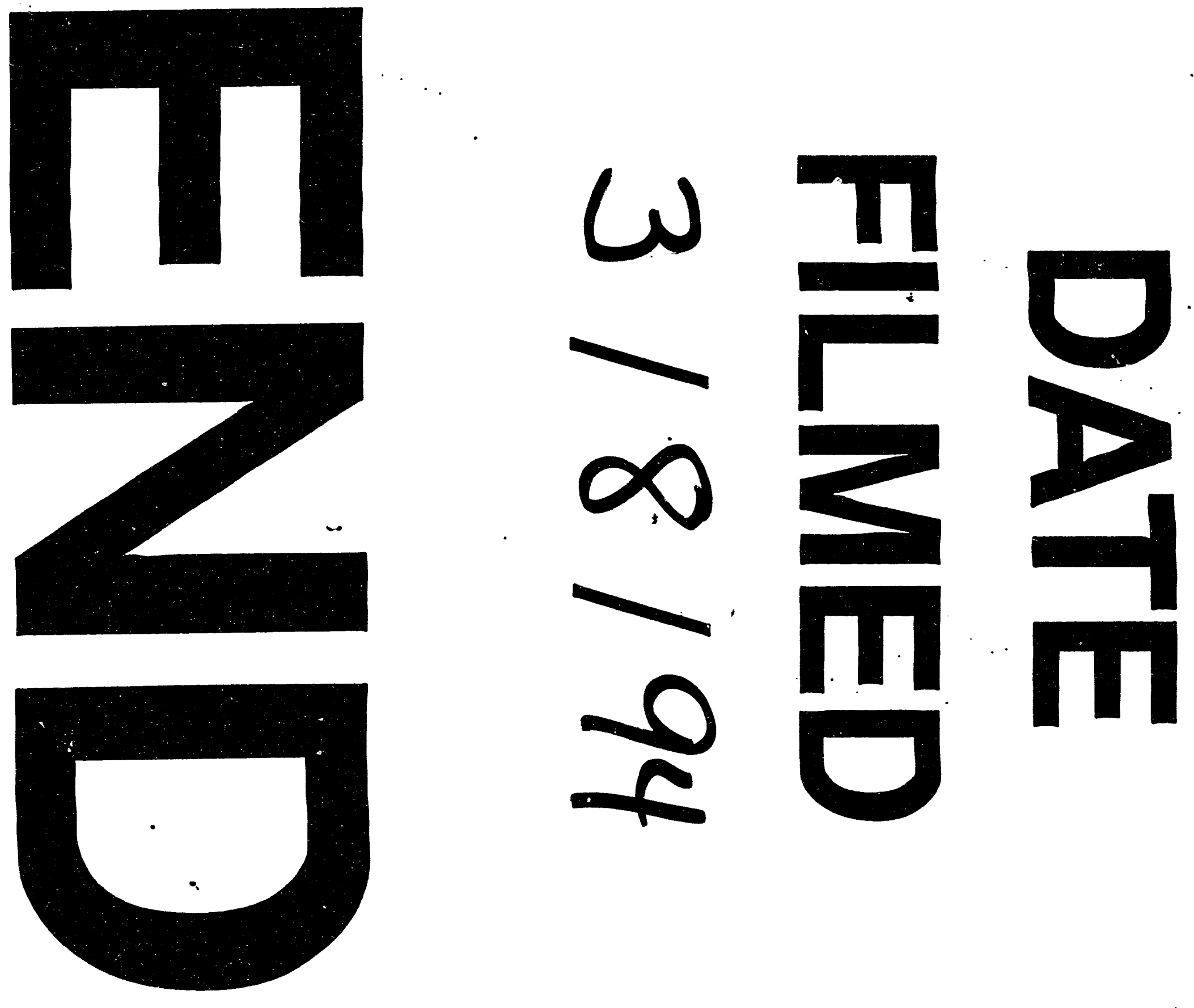
